\title{
Recurrence incidence of sudden infant death syndrome
}

\author{
S M BEAL AND H K BLUNDELL
}

Adelaide Children's Hospital, North Adelaide, Australia

SUMMARY The incidence of sudden infant death syndrome (SIDS) between birth and 2 years of age in South Australia was found to be $2 \cdot 1 / 1000$ live births. The incidence in previous siblings was 10 times that expected, in second degree relatives five times, and in third degree relatives four ${ }_{\omega}^{\circ}$ times that expected for the community. The minimum incidence in the next subsequent sibling $0_{0}^{\circ}$ was five times that expected. Except for one family in which both twins died during the same $N$ night, the surviving twin has never died (23 infants). The incidence of SIDS in adopted infants ${ }_{\circ}^{+}$ was similar to the incidence in natural born infants. Families in which two or more siblings died ${ }_{-}^{3}$ from SIDS differed from families in which only one infant died from SIDS in several ways. More $\gg$ infants were over 12 months old, and the mothers had an increased incidence of previousco miscarriage and threatened miscarriage during the pregnancy with the infant who died. In one $\stackrel{5}{\oplus}$ family both infants had bronchomalacia, and two families were severely socially deprived. $\vec{\varphi}$

For most families $(92 \%)$ in which an infant died from SIDS the risk of recurrence is small (less $\infty_{\infty}^{\infty}$ that twice the expected risk). We have identified a small subgroup (8\%) with a significantly increased risk of recurrence.

The sudden infant death syndrome (SIDS) is the death of an infant unexpected by history, and unexplained after thorough necropsy. The incidence in South Australia between 0 and 730 days during the last 15 years was $2 \cdot 1 / 1000$ live births, between 2 weeks and 2 years it was $2 \cdot 0 / 1000$, between 1 week and 1 year 1.9/1000, and between 1 month and 1 year $1 \cdot 8 / 1000$ live births.

Sudden unexpected infant death in siblings was reported by Platerus 1 in 1614 , and in cousins by Cheever ${ }^{2}$ in 1863 . The incidence among previous siblings has been reported as 10 times that expected. ${ }^{34}$ The incidence in all subsequent siblings was reported as $2 \cdot 1 \%$, and in the next subsequent sibling as $1.9 \%$ by Peterson, ${ }^{5}$ and the incidence in all subsequent siblings as 3.7 times and the next subsequent sibling as 4.4 times the community incidence in Norway. ${ }^{6}$ Emery described 12 families with two or more cot deaths. ${ }^{7}$

\section{Subjects and methods}

FAMILY HISTORY CONTROL SERIES

Between January 1973 and December 1978 one or both the authors visited the homes of 198 infants who died suddenly and unexpectedly, usually within
24 hours of the infant being found dead, to interview and counsel the parents. One hundred and eighty $\vec{O}$ seven of these infants died from SIDS. As a result of 3 these interviews it seemed that in some of the families there was a higher incidence of sudden unexplained death in infancy than would be expected. In an attempt to verify this impression a controlled series was undertaken (table 1).

Permission was granted by the Kindergarten Union to ask the parents of kindergarten children too participate in the study. Using the child at kindergarten as the index case, the mother was asked to음 complete a questionnaire in which she provided $>$ information about first, second, and third degree relatives of the child. A similar questionnaire was N sent to the parents of the previous 60 children who' had had SIDS. Information was sought about the total number of first, second, and third degree $N^{-}$ relatives, and about all deaths occurring between birth and 2 years, with the age at death and cause ofo death if known.

Because some of the relatives included in the $\stackrel{?}{+}$ questionnaire would have died before SIDS was classified as a disease, there was a certain degree of ${ }_{\bar{D}}^{\circ}$ subjectivity as to whether the death should be $\stackrel{\square}{\oplus}$ classified as SIDS. All cases diagnosed as 'silent $\stackrel{\otimes}{\circ}$ 
Table 1 Infant mortality in first, second, and third degree relatives of infants who died from SIDS compared with infants who died from other causes

\begin{tabular}{|c|c|c|c|c|c|c|}
\hline \multirow[t]{2}{*}{ Relative (degree) } & \multicolumn{3}{|c|}{ Infants who died from SIDS $(n=60)$} & \multicolumn{3}{|c|}{ Infants who died from other causes $(n=53)$} \\
\hline & $\begin{array}{l}\text { No who died } \\
\text { from SIDS }\end{array}$ & $\begin{array}{l}\text { No who died } \\
\text { from other causes }\end{array}$ & $\begin{array}{l}\text { Total No } \\
\text { of relatives }\end{array}$ & $\begin{array}{l}\text { No who died } \\
\text { from SIDS }\end{array}$ & $\begin{array}{l}\text { No who died } \\
\text { from other causes }\end{array}$ & $\begin{array}{l}\text { Total No } \\
\text { of relatives }\end{array}$ \\
\hline First & 3 & 1 & 172 & 0 & 0 & 156 \\
\hline Second & 6 & 6 & 747 & 1 & 6 & 446 \\
\hline Third & 13 & 17 & 1234 & 2 & 17 & 1519 \\
\hline Total No & 23 & 24 & 2153 & 3 & 23 & 2121 \\
\hline Rate/1000 & $10 \cdot 2$ & $11 \cdot 1$ & & 1.4 & $10 \cdot 8$ & \\
\hline
\end{tabular}

pneumonia', 'overwhelming infection', and 'suffocation' were included as SIDS. Where possible the relatives who remembered the death were interviewed and if the child died suddenly and unexpectedly at home without apparently being ill, and was between 1 and 6 months old, this was considered to be SIDS. The same criteria were applied to deaths in both groups. After this study it was decided to continue collecting family histories from families in which a death from SIDS had occurred. Because of the difficulty of verifying the cause of death in great aunts and great uncles they are excluded from the continuing study report covering 1979-1986 (table 2). The cause of death for parents' siblings, half siblings, nieces, and nephews was usually verified by the grandparents who were often present at the interviews, or were contacted by telephone. If there was any doubt, necropsy reports were studied.

Data collected in 1979 indicated differences in the obstetric histories of the mothers of infants who died of SIDS and who had a family history of SIDS, compared with those without such a history. ${ }^{3}$ This led to a search for differences between families which had had two infant siblings that died from
SIDS and families in which a single infant died from SIDS.

ESTABLISHING CAUSE OF DEATH OF INFANTS DYING IN SOUTH AUSTRALIA, 1965-1986

A list was made from records held at the office of the Registrar of Births, Deaths, and Marriages in Adelaide of the names of all children between the ages of 2 weeks and 2 years who died in South Australia between January 1965 and December 1985. This began in 1970 and was retrospective from 1965 to 1969 , but recorded from notification from 1970.

The causes of death were ascertained by studying necropsy reports as the Adelaide Children's Hospital. This uncovered $70 \%$ of all infant deaths in South Australia and $84 \%$ of sudden unexpected infant deaths. For those children who did not have a necropsy at the hospital a search of hospital records was made and if these mentioned potentially fatal disorders these were recorded. From this source we discovered a further $7 \%$. For the remainder the death certificate at the Registrar of Births, Deaths, and Marriages was examined. If the cause of death

Table 2 Incidence of previous SIDS in first, second, and third degree relatives of infants who died from SIDS

\begin{tabular}{|c|c|c|c|c|c|c|c|}
\hline \multicolumn{2}{|c|}{ Relatives (degree) } & \multirow{2}{*}{$\begin{array}{l}\text { Years } \\
1973-86\end{array}$} & \multicolumn{2}{|c|}{ Total No } & $\begin{array}{l}\text { No who died } \\
\text { from SIDS }\end{array}$ & $\begin{array}{l}\text { No of SIDS/ } \\
1000 \text { live births }\end{array}$ & \multirow{2}{*}{$\begin{array}{l}\begin{array}{l}95 \% \text { Confidence } \\
\text { intervals }\end{array} \\
9.5 \text { to } 33.0\end{array}$} \\
\hline First- & Siblings & & 660 & & 14 & $21 \cdot 2$ & \\
\hline Second- & $\begin{array}{l}\text {-Half siblings } \\
\text { Maternal aunts and uncles } \\
\text { Paternal aunts and uncles }\end{array}$ & $\begin{array}{l}1973-86 \\
1979-86 \\
1979-86\end{array}$ & & $\begin{array}{r}43 \\
673 \\
630\end{array}$ & $\begin{array}{r}1 \\
10 \\
3\end{array}$ & $\begin{array}{r}23 \cdot 3 \\
14 \cdot 9 \\
4 \cdot 8\end{array}$ & \\
\hline & Total second degree & & 1346 & & 14 & $10 \cdot 4$ & $4 \cdot 6$ to $16 \cdot 2$ \\
\hline Third- & $\begin{array}{l}\text { Mothers' half siblings } \\
\text { Fathers' half siblings } \\
\text { Maternal first cousins } \\
\text { Paternal first cousins }\end{array}$ & $\begin{array}{l}1979-86 \\
1979-86 \\
1979-86 \\
1979-86\end{array}$ & & $\begin{array}{r}20 \\
23 \\
639 \\
628\end{array}$ & $\begin{array}{l}1 \\
1 \\
6 \\
2\end{array}$ & $\begin{array}{r}50 \cdot 0 \\
43 \cdot 5 \\
9 \cdot 4 \\
3 \cdot 2\end{array}$ & \\
\hline & Total third degree & & 1310 & & 10 & $7 \cdot 6$ & 2.5 to $12 \cdot 7$ \\
\hline Total & & & 3316 & & 38 & 11.5 & 5.2 to 12.8 \\
\hline
\end{tabular}

Significant difference $(\mathrm{p}<0.0001)$ for first degree, second degree, and third degree relatives when compared with overall incidence of SIDS in South Australia $(2 \cdot 1$ per 1000$)$ using two tailed $z$ test. $^{8}$ 
was clear (for example, drowning) this was recorded, resulting in a further $20 \%$. For the remaining $3 \%$ in which the cause of death was not completely clear from the death certificate (for example, asphyxia) further information was obtained by either contacting the medical practitioner who signed the death certificate, or studying the necropsy reports at the office of the Attorney General's Department, or contacting the hospital where the infant died.

\section{OBTAINING CLINICAL, FAMILY, AND OBSTETRIC} HISTORIES

Since 1973 the families of most of the infants who died suddenly and unexpectedly $(99 \%$ of those in Adelaide, $80 \%$ in the whole of South Australia) have been interviewed by one or both of the authors, the first interview usually occurring within 24 hours of the infant being found dead or moribund. Data were recorded on a form. Several questions have been included since 1973; others have been added at varying times. Those relating to this paper include questions about parity and previous infant death (from 1973); previous miscarriage (from 1976); bleeding during pregnancy (from 1978); full family history, including total numbers of first to fifth degree relatives and all stillbirths, infant, child, and young adult deaths in first to fifth degree relatives (from 1979); and social grade. From 1977 families were given a rating from $1-5$ by the author after visiting the home. This was done subjectively by noting several factors including the type of house, the area in which they lived, the condition of the house and grounds, the education of both parents, and the present employment of the parents.

Data were obtained for families not interviewed from examination of birth certificates, contacting local doctors, and contacting hospitals where the infants were born.

\section{OBSTETRIC HISTORY CONTROL SERIES}

Questionnaires were sent to the mothers of 200 infants whose births were consecutively registered on two days in March 1984, three months after the birth was registered. Twelve were returned unknown at that address, for nine the infant was over 4 months of age when the reply was received, 20 did not reply. For seven infants the answers about obstetric history were not accurate enough for inclusion. One hundred and fifty two replies are included, which represents $81 \%$ of those mothers believed to have received the questionnaire.

\section{Results}

Between January 1970 and December 1985, 1726 infants in South Australia died between 2 weeks and
2 years of age. Six hundred and forty eight were classified as SIDS, an overall rate of 2.0/1000 live births. If the 15 infants who died from SIDS in the first two weeks of life, and the four 2 year old infants who died from undetermined causes in the same time span are included, the incidence of SIDS is $2 \cdot 1 / 1000$ live births.

\section{INCIDENCE OF SIDS IN FAMILIES}

The infant mortality among previous siblings in first, second, and third degree relatives of 60 children who died of SIDS and a control group of 53 children is shown in table 1. First degree relatives are siblings and parents; second degree relatives are half siblings, aunts, uncles, and grandparents; and third degree relatives are the parents's half siblings, cousins, great aunts, great uncles, and great grandparents. The incidence of SIDS in the families of infants who died of SIDS was much greater than in control families. The infant mortality from conditions other than SIDS was similar in the two groups.

Table 2 shows the incidence of SIDS among previous siblings in first, second, and third degree relatives. The previous incidence of SIDS among siblings, aunts, uncles, and cousins was ascertained from retrospective recall when the parents were interviewed. For siblings and half siblings data were collected from January 1973. For 213 families in which one or more infants died between January 1979 and July 1986 full family histories including data about all second and third degree relatives were collected.

Between January 1973 and July 1986545 infants died from SIDS. At the time of their death these infants had a total of 660 full siblings who were born alive. One infant had a twin sibling who died from SIDS in the same night. Thirteen other infants had a sibling (one infant, two siblings) who had previously died from SIDS (12 in South Australia, two in other states). Excluding the twin pair this is an incidence of $21 \cdot 2 / 1000$ siblings, or $10 \cdot 1$ times the expected rate. At the time of death the 545 infants who had died of SIDS had 43 half siblings; one of these had died from SIDS. The incidence among the full siblings of the parents was 13 in 1303 or $10.0 / 1000$ This is 4.7 times the expected risk. The incidence among the parents' half siblings, nieces, and nephews was 10 in 1310 or $7 \cdot 6 / 1000$ (3.6 times the expected risk). The incidence was higher among the mothers' relatives $(12 \cdot 8 / 1000)$ than among the fathers' relatives $(4 \cdot 7 / 1000)$.

Table 3 shows the incidence in the mothers' next child. Between January 1970 and September 1986 690 infants under 3 years of age died from SIDS Twelve families had two full siblings die from SIDS (including one pair of twins) and one mother had 
Table 3 Histories of families with two or more infants who died from SIDS between 1970 and 1976

\begin{tabular}{|c|c|c|c|c|c|}
\hline \multirow{2}{*}{$\begin{array}{l}\text { Family } \\
\text { No }\end{array}$} & \multirow[t]{2}{*}{ History } & \multicolumn{3}{|c|}{ Age at death (months) } & \multirow{2}{*}{$\begin{array}{l}\text { Next } \\
\text { child }\end{array}$} \\
\hline & & First child & Second child & Third child & \\
\hline 1 & Twin boys (died); two single boys (survived) & 5 & 5 & NA & 1 \\
\hline 2 & Two miscarriages; one boy (died); one girl (died) & 3 & 0 & NA & 1 \\
\hline 3 & Two boys (died); one girl and four boys (survived) & 14 & 4 & NA & 1 \\
\hline 4 & One girl (died); one boy (died) & 24 & 8 & NA & 1 \\
\hline 5 & One boy (died); one boy (survived); one boy (died) & 2 & 3 & NA & 0 \\
\hline 6 & $\begin{array}{l}\text { Four miscarriages; one girl (died); one miscarriage; } \\
\text { one boy (survived); one miscarriage; one boy (died) }\end{array}$ & 4 & 7 & NA & 0 \\
\hline 7 & $\begin{array}{l}\text { Three miscarriages; one stillbirth; one girl (died); } \\
\text { one neonatal death; one boy (survived); one boy (died) }\end{array}$ & 17 & 12 & NA & 0 \\
\hline 8 & One miscarriage; one girl (survived); two boys (died) & 6 & 0 & NA & 1 \\
\hline 9 & $\begin{array}{l}\text { Two miscarriages; one girl (survived); two boys (died); } \\
\text { one boy (survived) }\end{array}$ & 2 & 4 & NA & 1 \\
\hline 10 & One girl (survived); two boys (died); one boy (survived) & 1 & 8 & NA & 1 \\
\hline 11 & $\begin{array}{l}\text { One girl (survived); one girl (died); one boy (survived); } \\
\text { one boy (died) }\end{array}$ & 2 & 1 & NA & 0 \\
\hline 12 & $\begin{array}{l}\text { One miscarriage; one girl (survived); one boy (died); } \\
\text { one girl (survived); one girl (died) }\end{array}$ & 2 & 1 & NA & 0 \\
\hline 13 & $\begin{array}{l}\text { One miscarriage; one boy (survived); one girl (survived); } \\
\text { one miscarriage; one girl (died); one boy (died) }\end{array}$ & 1 & 2 & NA & 0 \\
\hline 14 & Two boys (died); one girl (died) & 2 & 19 & 1 & 2 \\
\hline
\end{tabular}

Families 4 and 14 -parity not gravidity known; family 8-half siblings (same mother). NA=not applicable.

two infants who died from SIDS who had different fathers. Two families had had a previous infant die from SIDS (including one of the families with two SIDS deaths between 1970 and 1986). One family had had an adopted infant who died from SIDS before 1970. Excluding the twin pair, for nine SIDS infants it was the next born sibling who died from SIDS (table 3). Of the 654 families in which one or more infants died from SIDS between 1970 and 1985, 17 mothers are known not to have had further children. The maximum number of next born siblings is therefore 637. Of these, seven infants are known to have died from SIDS. Therefore the minimum incidence in next born siblings is $11 \cdot 0 / 1000$, or 5.2 times the general population risk. The exact incidence in next subsequent siblings cannot be given, as some families who have moved from South Australia may have had another infant who died of SIDS and the exact number of subsequent siblings is not known. In South Australia the incidence of SIDS among twins is double the incidence among singletons. The increased risk is significant for twins weighing less than $2000 \mathrm{~g}$ at birth $(4.4$ times the expected risk) but not for twins weighing over $2000 \mathrm{~g}$ at birth (78\% of twins). Between 1970 and 1986 three infants who died from SIDS had had a twin die previously (one early intrauterine, one late intrauterine, and one intrapartum death). One pair of twins both died during the same night. Twenty three twins were found dead while their twin was alive. Five surviving twins have used home apnoea alarms.
No surviving twin of a SIDS victim has subsequently died. One triplet has died from SIDS, the other two remain alive and well.

The number of infants adopted in South Australia has fallen steadily since 1970 , and in the year July 1970 to June 1971, 635 infants under 1 year of age were adopted. By the year July 1973 to June 1974 this had fallen to 266 . In the four year period July 1970 to June 1974 a total of 1704 infants under 1 year of age were adopted. Of these, four infants died from SIDS $(2 \cdot 3 / 1000)$. In 1971 a twin boy aged 3 months died from SIDS. As well as his twin he had two natural siblings. An adopted sibling aged 1 month had died from SIDS six years earlier.

SIDS IN SIBLINGS

Table 4 shows the ages of siblings who died from SIDS were more variable than the ages of SIDS victims without SIDS in a sibling, one fifth of siblings who died from SIDS being over 12 months of age. Thirty six infants over 12 months of age died from SIDS between 1970 and 1985 . Two of these were siblings. Of the 35 families who had an infant over 12 months of age with SIDS, four had a recurrence in a sibling $(11 \%)$. Of 676 first SIDS in a family $641(95 \%)$ were under 12 months of age. The recurrence in families who had a child die from SIDS in this age range was eight in 641 families $(1 \%)$.

There were also unexpected, unexplained deaths in children and young adults. In the family with three infants who died from SIDS, the father's 
Table 4 Age at which infants died of SIDS in South Australia, January 1970-September 1986

\begin{tabular}{|c|c|c|}
\hline Age at death & $\begin{array}{l}\text { Single deaths } \\
\text { from SIDS } \\
(n=662) \\
\text { No }(\%)\end{array}$ & $\begin{array}{l}\text { Deaths from SIDS } \\
\text { among siblings } \\
(n=25) \\
\text { No }(\%)\end{array}$ \\
\hline$<7$ days & $4(0 \cdot 6)$ & 0 \\
\hline $7-14$ days & $11(2)\} 40(6)$ & $1(4)$ \\
\hline 14-30 days & $25(4)$ & $1(4)\}^{2}(8)$ \\
\hline 1-6 months & $505(76)$ & $14(56)$ \\
\hline $6-12$ months & $86(13)$ & 4 (16) \\
\hline $12-24$ months & 28 (4) & $4(16)\}_{5}$ \\
\hline $24-30$ months & $3(0 \cdot 5)\}^{31(3)}$ & $1(4)\}^{3}(20)$ \\
\hline
\end{tabular}

These figures exclude twins who died at 5 months, two siblings who died elsewhere at 2 and 4 months, respectively, and one infant whose adopted sibling died before 1970 .

mother died suddenly at 29 years and no cause for death was found at necropsy. In a family who moved to South Australia after two infants had died from SIDS in New South Wales, the father died at the age of 28 while he was sitting with friends after a game of squash. He showed no signs of distress before his sudden death for which no cause could be found at necropsy. His sister at 24 years of age collapsed while dressing to go out; she was ventilated by bag and mask in the ambulance and given artificial ventilation in hospital, but she never regained consciousness and died. She had had asthma in the past and at necropsy hypoxic brain damage was found, thought to be secondary to asthma. The cousin of another family in which two siblings had died from SIDS was running across the lawn at the age of 2 when she collapsed and died. Heart failure was diagnosed, although until the time of her death she had seemed completely healthy.

During the past eight years details of all deaths of children and young adults have been obtained from the 274 families interviewed whose infants have died from SIDS. Only one family with a single infant dying from SIDS has described such an unexpected unexplained death.
Table 5 shows the incidence of SIDS according to the mothers' obstetric histories. Though history of previous miscarriage was recorded from 1976, a history of bleeding in the first three months of pregnancy has only been sought since 1978 . In the last 206 families with one infant dying from SIDS the incidence of previous miscarriage and bleeding in the first three months of pregnancy was no higher than in the mothers of a cohort of 152 successively registered singleton infant births.

In 12 families in which a sibling died of SIDS (including one family with SIDS before 1970) eight mothers had had at least one miscarriage before the first death from SIDS (table 3). One of these had two further miscarriages between the two infants who died from SIDS, and one a neonatal death of an extremely premature infant between the two deaths from SIDS. Details were obtained about bleeding in pregnancy for 16 of those in which a sibling had died of SIDS; eight pregnancies had been complicated by vaginal bleeding during the first three months. One further pregnancy was complicated by bleeding at four months' gestation. In the remaining seven pregnancies there was no bleeding. Previous stillbirth of a normally formed infant occurred in one of 12 families in which two siblings had died from SIDS and five of 413 families in which one infant had died from SIDS.

Some unusual pathological findings were recorded. In reviewing the histological reports of some of the siblings who had died of SIDS, Professor J Emery (personal communication) noted bronchomalacia in both boys in one family. He did not feel that this was sufficient explanation for death, but had never observed this before in many hundreds of infants with SIDS. Interestingly, one of the brothers who died from SIDS at 3 months of age was noted to have an odd cry, described by the parents as 'like a bleating sheep'. His sibling who died at 2 months of age had had a pyloroplasty at 14 days of age. Recovery from anaesthetic took longer than expected but he was otherwise well. At 5 weeks of age he had an episode of loud gasping

Table 5 Comparison of obstetric complications among the groups

\begin{tabular}{|c|c|c|c|c|c|c|}
\hline & \multicolumn{3}{|c|}{ Previous miscarriage } & \multicolumn{3}{|c|}{$\begin{array}{l}\text { Vaginal bleeding during first } \\
\text { three months of pregnancy }\end{array}$} \\
\hline & No & $\%$ & $\begin{array}{l}95 \% \text { Confidence } \\
\text { intervals }\end{array}$ & No & $\%$ & $\begin{array}{l}95 \% \text { Confidence } \\
\text { intervals }\end{array}$ \\
\hline $\begin{array}{l}\text { Control group }(n=152) \\
\text { Mothers with a single death from SIDS }(n=206) \\
\text { Mothers with more than one death from SIDS } \\
\quad(n=12 \text { for miscarriage and } 16 \text { for vaginal bleeding) }\end{array}$ & $\begin{array}{l}36 \\
39\end{array}$ & $\begin{array}{l}23 \cdot 7 \\
18 \cdot 9 \\
66 \cdot 7^{*}\end{array}$ & $\begin{array}{l}16 \cdot 6 \text { to } 30 \cdot 8 \\
13 \cdot 3 \text { to } 24 \cdot 5\end{array}$ & $\begin{array}{l}23 \\
21\end{array}$ & $\begin{array}{l}15 \cdot 1 \\
10 \cdot 2\end{array}$ & $\begin{array}{l}9.1 \text { to } 21.2 \\
5.8 \text { to } 14.6 \\
14.0 \text { to } 86.0\end{array}$ \\
\hline
\end{tabular}

${ }^{*}$ Significant difference $(\mathrm{p}<0.005)$ when compared with mothers with a single death from SIDS, using $\chi^{2}$ test with one degree of freedom. 
followed by shallow breathing, which lasted for about 10 minutes during which he was cold and clammy all over. The father of the two boys had chest pain and cough with every upper respiratory infection and required admission to hospital with pneumonia when 26 years old. The paternal grandfather often had episodes of gasping for air as a young adult and became extremely breathless with upper respiratory infections. He caught a 'cold' at 62 years, began gasping for breath, was admitted to hospital but died four days later from upper respiratory infection. The paternal grandmother's brother (third degree relative) had been found dead in his cot, having been thought well, at 7 weeks of age. In another family who now have five living children, the first was admitted to hospital at 14 months of age having swallowed cleaning fluid. He developed mild pneumonitis, was well following discharge from hospital, but was found dead in his cot 10 days later. At necropsy there were multiple foreign body granulomata in the lungs, although the lungs were well aerated. The second child in the family was found dead in his cot at 4 months of age; there were no unusual histological findings.

The homes of 445 infants who died from SIDS have been visited by one of us in the past 13 years; 14 families lived in severely deprived conditions. Two of these families have had a further death from SIDS, one of them being the most severely deprived of all homes visited.

None of the families with recurrence in a sibling in this series had a history of SIDS in a second degree relative. There was one in which SIDS occurred in a third degree relative, and one in a fifth degree relative. Of the 213 families studied in detail, one mother had two brothers who died from SIDS, and another infant's father's brother and the mother's half brother had died from SIDS. The first infant of this mother had one episode of pronounced apnoea requiring mouth to mouth resuscitation, the second infant died from SIDS, and the third infant (who required regular thyroid supplement for congenital hypothyroidism) had several attacks of apnoea while on a home alarm system.

\section{Discussion}

In Norway all live births are recorded in a Medical Birth Registry. ${ }^{6}$ The official national person number system enables longitudinal follow up of all mothers to be carried out with respect to the results of their pregnancies. This is linked to the official system of death registration. Apart from families who may emigrate this enables accurate evaluation of recurrence of SIDS in subsequent siblings. It seems that in that series the recurrence is in the mother's next subsequent child, which includes half siblings on the mother's but not the father's side. Using this system and including deaths occurring between 7 and 364 days of age, SIDS in the next subsequent sibling (? mother's next child) in Norway was found to be 4.4 times the expected incidence. Such a numbering system is not used in South Australia, so the exact number of next subsequent infants is not known. Most mothers in South Australia who have an infant who dies from SIDS have further children; $81 \%$ of married couples who had an infant that died from SIDS in 1980 are known to have had a subsequent child by January 1986 , and $72 \%$ of mothers in Adelaide who had an infant that died from SIDS in 1985 had become pregnant by July 1986 .

In the same age range as the Norwegian study (7 to 364 days) between 1970 and 1985, 603 of the families that we studied had their first infant die from SIDS in South Australia. Of these mothers eight have had a further death in the same age range, four in the next subsequent child. Extrapolating from the previous data that showed that $81 \%$ of families in which a child died from SIDS in 1980 had another child by 1986 , it is thought that between $80 \%$ and $100 \%$ of such mothers have another child. This means that the incidence in the next subsequent child in the 7 to 364 days age group may be estimated as being between 4 in 693 and 4 in 482 , or a rate of $6 \cdot 7$ to $8 \cdot 3 / 1000$ which is 3.5 to 4.4 times the rate expected in this age range (1.9/1000); this is similar to the relative risk in Norway. When infants dying at 12 to 24 months are included, between 1970 and 1985 a further 35 families had their first infant die from SIDS in South Australia. Of these four had a recurrence, three in the next subsequent infant, making a total of seven in the mother's next subsequent child in a maximum of 638 , or a minimum rate of $11 / 1000$, five times the expected rate of $2 \cdot 1 / 1000$ in this age range.

Peterson found mothers in families in which more than one infant had died from SIDS had considerably fewer full brothers and sisters and proportionately more half, step, or adopted siblings than their spouses and the mothers and fathers of all other SIDS probands. ${ }^{5}$ In the families with more than one case of SIDS in this study one mother was adopted. Ten mothers had 41 siblings (including one neonatal death of a full sibling) and four half siblings. Ten fathers had 32 siblings, one stillborn full sibling, two half siblings, and one step sibling (who died from SIDS).

Both genetic and environmental factors seem to contribute to recurrence of SIDS in families in South Australia, and indeed the gestation and environment of infant siblings tends to be similar. The 
environmental influence is illustrated by the occurrence of SIDS in two infants in one family, one being natural born and the other adopted; the only incidence of both twins dying being in the same night; and the recurrence in two severely socially deprived families. The genetic influence is shown in the three families with deaths in young adults or children and the family in which two infants had bronchomalacia.

In 1980 in South Australia the average family size was 2.4 children. Assuming SIDS to be a sporadic event this means an incidence of SIDS of about one in every 200 families. Between January 1970 and September 1986, 677 families in South Australia had an infant who did from SIDS; for 13 families it was a recurrence of SIDS. This is an incidence of one in 52 families, or about four times the expected risk.

Six hundred and twenty six of the 677 families $(92 \%)$ had their first infant death from SIDS between 2 weeks and 12 months of age, were not severely socially deprived, had no family history of sudden unexpected unexplained deaths in children or young adults, and no bronchomalacia at necropsy. Five of these familes have had a subsequent infant die from SIDS (an incidence of one in 126 families, or 1.6 times that expected), three of these being the next subsequent child $(0.5 \%$ incidence in next child). It seems reasonable to reassure these families that it is unlikely to happen again.

The risk for a few families (less than $10 \%$ of SIDS) is significantly increased. The only family with bronchomalacia found at necropsy, three out of four families with a history of sudden unexpected unexplained deaths in children or young adults, four of 35 families in whom the infant who died from SIDS was over 12 months of age at the time of death, and two of the 14 families who were felt to be severely socially deprived, had a recurrence in a sibling. Although numbers in this study are too small to give exact risks, in families with any of these factors, particularly if the mother has a history of miscarriage or bleeding during the pregnancy, the subsequent child should be considered 'at risk'.

Recurrence in families relates to the incidence in a community or race. Where the incidence is low-for example in Sweden or Asia-recurrence is extremely rare. It also relates to the size of the family; the more infants born into a family the more likely is it that there will be a recurrence. There are many reasons for large families (cultural and religious) but good counselling at the time of the death from SIDS and the increased appreciation by parents of the importance of children and families, are likely to explain part of the difference in reported family recurrences in different communities.

\section{References}

' Platerus F. Observationum in hominis affectibus plerisque-libri tres. Basillae 1614, 172, cited in Major RH, Classical Descriptions of Disease. Springfield: Collegiate Press of Minnesota, 1932.

2 Cheever D. Sudden death of an infant without known cause. Boston Medical and Surgical Journal 1863;68:224.

${ }^{3}$ Beal SM. Some epidemiological factors about sudden infant death syndrome (SIDS) in South Australia. In: Tildon JT, Roeder LM, Steinschneider A, eds. Sudden infant death syndrome. New York: Academic Press, 1983:15.

${ }^{4}$ Froggatt P, Lynas M. Mackenzie G. Epidemiology of sudden unexpected death in infants ("cot death") in Northern Ireland. British Journal of Preventive and Social Medicine 1971;25:119.

5 Peterson DR, Chinn NM, Fisher LD. The sudden infant death syndrome-repetition in families. J Pediatr 1980;97:265.

- Irgens LM, Skjaerven R, Peterson DR. Prospective assessment of recurrence risk in sudden infant death syndrome siblings. $J$ Pediatr 1984;104:349-51.

${ }^{7}$ Emery JL. Families in which more cot deaths have occurred Lancet 1986;i:313-5.

${ }^{\star}$ Snedecor GW, Cochran WG. Statistical methods. 6th ed. Ames: lowa State University Press, 1967.

Correspondence to Dr S Beal, Adelaide Children's Hospital, North Adelaide, SA 5066, Australia.

Accepted 25 January 1988 